\title{
Analysis of the tensile behavior of a TWIP steel based on the texture and microstructure evolutions
}

\author{
D. Barbier ${ }^{\mathrm{a}, \mathrm{b}}$, N. Gey ${ }^{\mathrm{a}, *}$, S. Allain ${ }^{\mathrm{c}}$, N. Bozzolo ${ }^{\mathrm{a}}$, M. Humbert $^{\mathrm{a}}$ \\ a Laboratoire d'Etude des Textures et Application aux Matériaux (LETAM), UMR CNRS 7078, Université Paul Verlaine-Metz, 57000 Metz, France \\ ${ }^{\mathrm{b}}$ Laboratoire de Physique et Mécanique des Matériaux (LPMM), UMR CNRS 7554, Université Paul Verlaine-Metz, 57000 Metz, France \\ c ArcelorMittal Research SA, Voie Romaine, BP 30320, 57283 Maizières-les-Metz, France
}

\section{A R T I C L E I N F O}

Keywords:

Austenitic steel

TWIP effect

Tension test

EBSD

Deformation texture

\begin{abstract}
A B S T R A C T
The texture and microstructure evolutions of a fine-grained TWIP steel subjected to tensile tests at room temperature were investigated in relation to the mechanical behavior. This steel combines both high ductility and strength owing to the TWIP effect. Also the steel exhibits a high strain hardening rate that evolves according to five stages, which are related to the microstructure and texture evolutions and characteristics. The formation of nano-twins in the initial stage of deformation leads to an increase in strain hardening rate. The development of the pronounced $\langle 111\rangle$ fiber in the tensile direction sustains mechanical twinning and maintains the strain hardening rate on a high level. The resulting microstructure exhibits several types of twin configurations and sub-boundaries with high misorientations due to intense activities of dislocation glide. The twin volume fraction was estimated to be $9 \%$ at the final stage of tensile deformation. The new orientations generated by mechanical twinning do not change considerably the final texture.
\end{abstract}

\section{Introduction}

Since few years, the ongoing research of the steel industry mainly focuses on high strength steels with excellent formability. This optimal combination is particularly attractive for automotive applications such as structural reinforcements and energy absorption parts. The increase in strength enables to reduce the mass of the car bodies whereas the increase in ductility admits complex component design. Among the wide variety of recently developed steels, high manganese austenitic steels with low stacking fault energy (SFE) are particularly promising, especially when mechanical twinning occurs $[1,2]$. Outstanding mechanical properties combining a high ductility and high strength are then obtained. This compromise often observed in low SFE fcc materials results from a high strain hardening rate. Asgari et al. [3] reported the evolutions of the strain hardening rate according to different stages independent of the grain size in low SFE materials and analyzed each stage in relation to the microstructure evolution.

In Fe-Mn-C austenitic steels, mechanisms responsible for the high strain hardening rate are still under discussion [4-6]. Some authors attribute the high strain hardening rate to dynamic strain

\footnotetext{
* Corresponding author. Tel.: +33 387315385; fax: +33 387315377.

E-mail address: nathalie.gey@univ-metz.fr (N. Gey).
}

aging (DSA) mechanisms, interpreted as the interaction between C-Mn bonds and mobile dislocations [4,7,8]. Bracke et al. [9] suppressed the DSA in a $\mathrm{Fe}-22 \mathrm{Mn}-0.6 \mathrm{C}$ (composition given in mass percent) steels by substituting carbon by nitrogen, while keeping the SFE constant. The resultant mechanical properties were the same. Mechanical twinning can also be a dominant mechanism to increase the strain hardening rate. As the strain increases, the occurrence of twins reduces the mean free path of dislocations. This is called TWinning Induced Plasticity (TWIP) effect that can be interpreted as a dynamical Hall-Petch effect [10-14]. Allain $[13,14]$ suggested that the high strain hardening rate of $\mathrm{Fe}-\mathrm{Mn}-\mathrm{C}$ TWIP steels is mainly due to mechanical twinning. More recently, Bouaziz et al. [15] have shown that the strain hardening rate in the $\mathrm{Fe}-22 \mathrm{Mn}-0.6 \mathrm{C}$ steel is mainly of kinematical origin which is linked to the TWIP effect.

Only few studies are related to the microstructure evolution during the deformation of Fe-Mn-C TWIP steels. The microstructure has been characterized either by optical microscopy (low spatial resolution) or by transmission electron microscopy investigations giving accurate local data but which are insufficient for statistical deductions $[13,16]$. These studies have shown that the austenite grains contain bundles of nano-twins with different configurations [10-13]. Up to now, few attention has been addressed to the corresponding texture evolution and its interaction with twinning $[16,17]$. These parameters are the key to better understand the high strain hardening rate of TWIP steels. 
The aim of this research is to provide a detailed description of the deformation mechanisms of a Fe-Mn-C TWIP steel deformed in tension. In particular the dependence of twinning on the grain size and grain orientation is analyzed. For this purpose, the microstructure and texture evolutions have been characterized in great detail by performing X-ray diffraction, EBSD with a FEG-SEM and TEM. Interactions between twinning and texture evolution are analyzed. Moreover we estimated the twin volume fraction from its effect on the texture formation. Finally, the transitions of subsequent strain hardening stages were analyzed in relation to microstructure and texture features.

\section{Experimental procedures}

\subsection{As-received material}

A fine-grained Fe-Mn-C TWIP steel was supplied by ArcelorMittal Research SA Maizières as a $1.3 \mathrm{~mm}$ thick sheet. The alloy designation of the steel is $22 \mathrm{Mn}-0.6 \mathrm{C}$ (composition in mass percent, balance iron). The high manganese content stabilizes the austenitic phase at room temperature and decreases the SFE to about $20 \mathrm{~mJ} \mathrm{~m}^{-2}[2,18]$. Consequently, mechanical twinning occurs during deformation at room temperature $[2,18]$. At lower temperature, as the SFE is decreased, $\varepsilon$ martensite is formed.

The initial microstructure shows equiaxed $\gamma$ grains with an average size of $2.6 \mu \mathrm{m}$. However, the grain size varies within a large range from about $0.5-15 \mu \mathrm{m}$. Grains larger than $5 \mu \mathrm{m}$ are less numerous (about $10 \%$ ) but they represent $40 \%$ of the material surface. The initial texture is rather weak with a texture index (TI) value of 1.23, as shown in Fig. 2a.

\subsection{Tensile tests}

Tensile tests were conducted at room temperature by applying a strain rate of $10^{-3} \mathrm{~s}^{-1}$ (quasi-static loading conditions). The tensile samples were cut out of the sheet parallel to the transverse direction (TD). The gauge length was $80 \mathrm{~mm}$ and the width $20 \mathrm{~mm}$, respectively. One tensile test was conducted up to the rupture. Six others tensile samples were uniformly strained with $0.02,0.05,0.10$, $0.20,0.30$ and 0.40 true strain. The true stress and inelastic strain were calculated and the normalized strain hardening rate, defined as $(\mathrm{d} \sigma / \mathrm{d} \varepsilon) / G_{0}$, as well. $\mathrm{G}_{0}$ is the shear modulus at room temperature which was determined to be $62 \mathrm{GPa}$ according to the elasticity relation $G_{0}=E / 2(1+v)$. The Young modulus E and the Poisson coefficient $v$ were determined experimentally. The strain hardening rate was calculated from the experimental true stress true strain curve, fitted with a 7 th order polynomial function.

\subsection{Microstructure and texture characterization}

The EBSD technique was used to analyze the local texture in relation to the microstructure. For this purpose, high resolution orientation maps were acquired in a 6500F JEOL field emission gun-scanning electron microscope (FEG-SEM) equipped with the Channel 5 EBSD system (HKL Technology). Orientation maps with a beam step between 20 and $70 \mathrm{~nm}$ were taken from a large number of grains of the as strained samples. They were at first prepared by standard grinding and polishing. An additional surface treatment by using ion milling facility (BalTec RES 010) improved the quality of the Kikuchi patterns of the deformed samples with more than 0.3 true strain. Despite this careful preparation, the Kikuchi pattern indexing rate decreased from $95 \%$ for the undeformed to $65 \%$ for the samples deformed at 0.55 true strain.

The results of the EBSD scans are displayed as Kikuchi pattern quality (KPQ) maps and additional orientation maps. These reveal the local texture, the intra-granular misorientation gradients induced by the deformation and interesting details of the microstructure such as grain and twin boundaries [19], respectively. The orientation coloring code used in this paper is given by the standard triangle of the inverse pole figure (IPF) with TD projected in the cubic reference frame: grains misoriented by less than $20^{\circ}$ with respect to the $\langle 100\rangle,\langle 110\rangle,\langle 111\rangle / /$ TD fiber orientations are red, green and blue, respectively.

To analyze the intra-granular misorientations produced by the deformation, the grain orientation spread was quantified as follows: (1) pixels belonging to the same grain are detected with a misorientation criterion of $3^{\circ}$ applied from one pixel to the next, (2) the mean grain orientation is calculated and finally (3) the average misorientation between each pixel orientation and the mean grain orientation are deduced. This average misorientation characterizes the long range orientation spread and is called internal orientation spread (IOS). This parameter is grain size dependant.

The microstructure was also investigated in a FEI CM 200 TEM to take advantage of a higher spatial resolution. The samples were mechanically polished to $80 \mu \mathrm{m}$ in thickness and the TEM foils were electrolytically thinned to electron transparency by using TENUPOL thinning facility and a 5 vol.\% perchloric acid/95 vol.\% acetic acid solution at $30 \mathrm{~V}, \mathrm{DC}$. In order to check that the thin foil preparation did not induce the formation of artifact dislocations and mechanical twins, the as-received material was also prepared for TEM examination.

The deformation textures were determined from the $\{200\}$, $\{220\}$ and $\{111\}$ pole figures. These were measured by X-ray diffraction (XRD) using a Siemens D5000 goniometer $\left(\mathrm{Cr} \mathrm{K} \mathrm{K}_{\alpha}\right.$ radiation). The experimental data were processed to obtain the orientation distribution function $f(g)$ (ODF) [20]. The orthorhombic
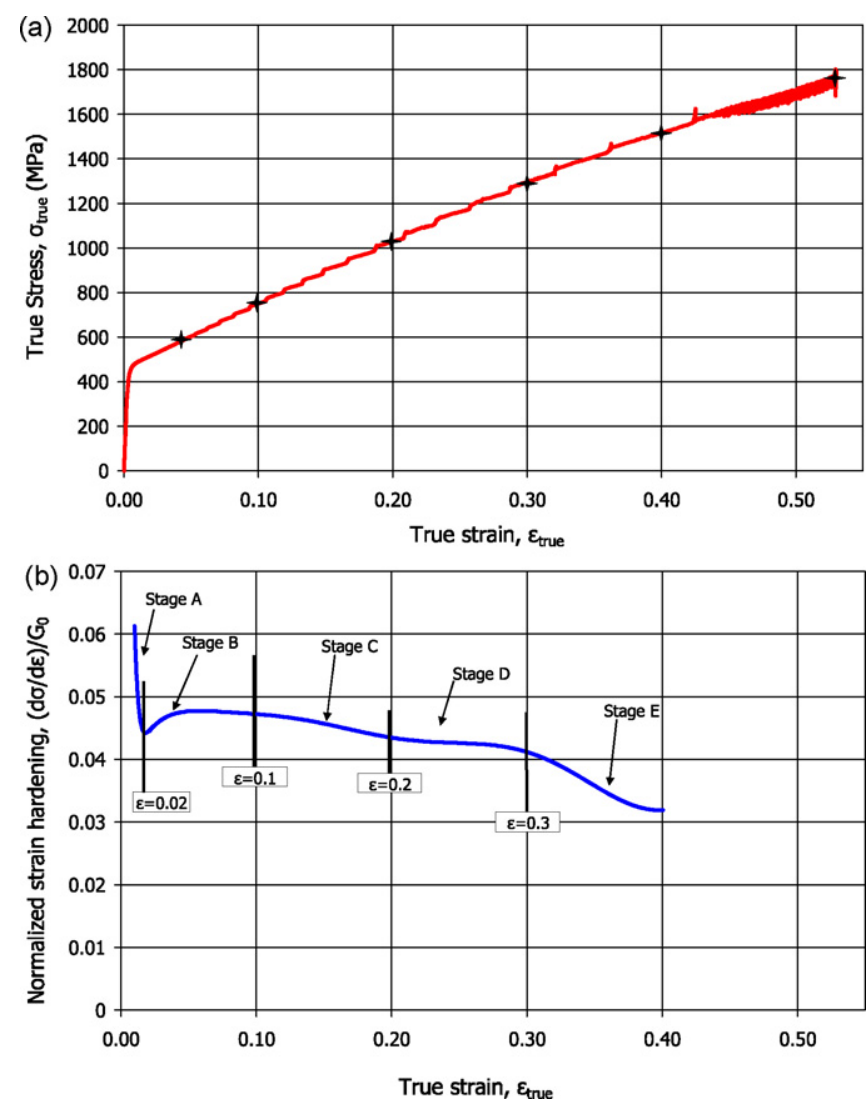

Fig. 1. True stress true strain curve (a) and normalized strain hardening rate curve as a function of the true strain (b) of the Fe-22Mn-0.6C fine-grained TWIP steel. 
(a)

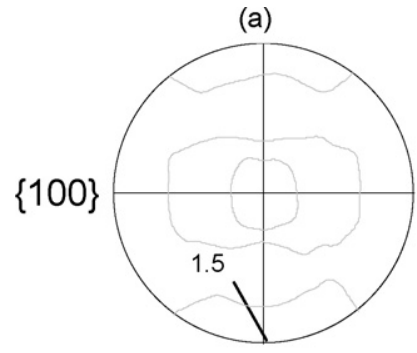

$\{111\}$

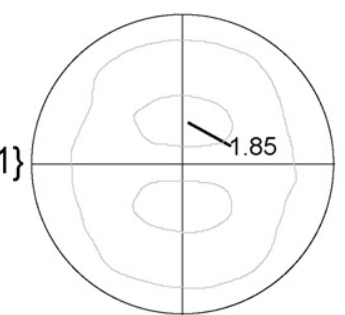

$\phi_{1}$

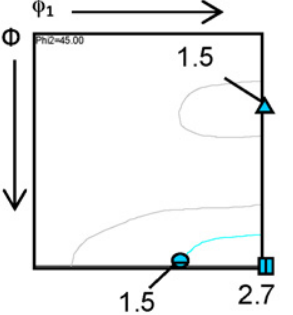

(b)
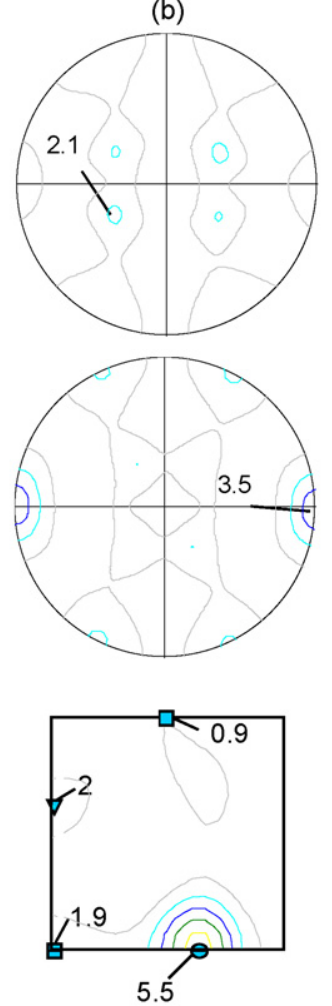

(c)
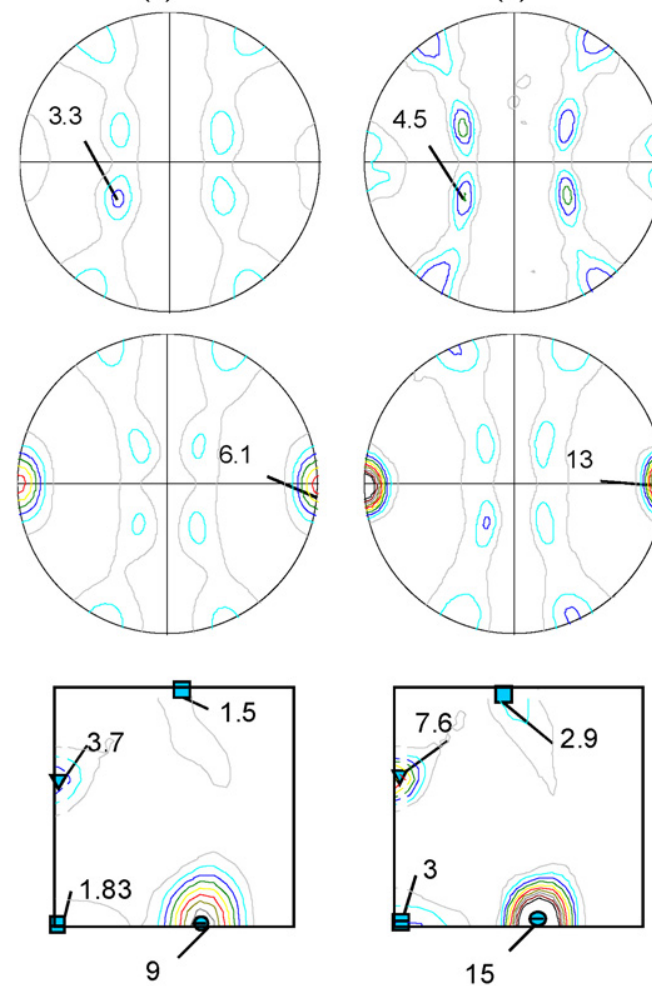

(d)
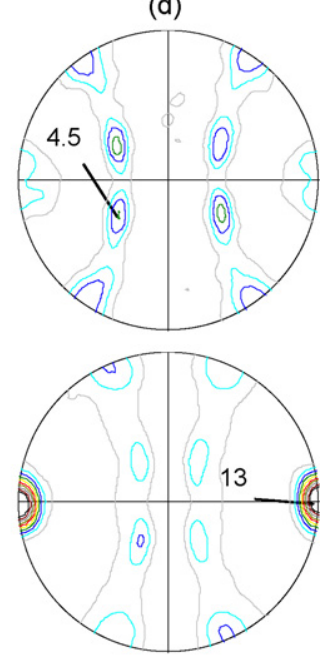

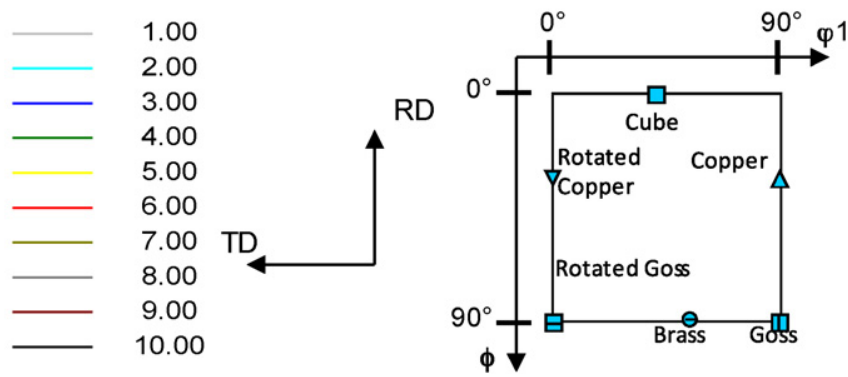

Fig. 2. $\left\{\begin{array}{lll}1 & 0 & 0\end{array}\right\}$ and $\left\{\begin{array}{lll}1 & 1 & 1\end{array}\right\}$ pole figures and $\varphi_{2}=45^{\circ}$ ODF section at different true strain levels: as-received (a), 0.2 (b), 0.3 (c) and 0.55 (d).

symmetry, clearly displayed by the pole figures, was imposed for the calculation of the ODF. The TI defined as $\mathrm{TI}=\oint f(g)^{2} \mathrm{~d} g$ describes quantitatively the texture sharpness. In this paper, the texture is represented by the $\left\{\begin{array}{lll}1 & 0 & 0\end{array}\right\}$ and $\left\{\begin{array}{lll}1 & 1 & 1\end{array}\right\}$ pole figures and the $\varphi_{2}=45^{\circ}$ ODF section in the Euler space.

The main texture components are described according to the $\{\mathrm{khl}\}<\mathrm{uvw}>$ notation $(\{\mathrm{khl}\}$ being the plane parallel to the rolling plane and $<\mathrm{uvw}>$ being the direction parallel to the rolling direction at $90^{\circ}$ from the tensile direction. The volume fraction of each texture component was calculated by taking a tolerance of $10^{\circ}$ around the strict orientation into account. The largest Schmid factors (SF) for slip and for twinning were calculated for each texture component as presented in Table 1 . The $\{111\}<110>$ slip systems and the $\left\{\begin{array}{lll}1 & 1\end{array}\right\}<112>$ twinning systems were considered.

\section{Results}

\subsection{Mechanical behavior}

The Fe-Mn-C steel exhibits outstanding mechanical properties combining high ductility and extraordinary strength. The ultimate tensile strength amounts to $1000 \mathrm{MPa}$ and more and the elongation to rupture is over $70 \%$. The true stress and the normalized strain hardening rate are plotted versus the true strain in Fig. 1a and b, respectively. Markers indicating each interrupted tensile tests are attached on both curves. Serrations on the stress-strain curve were observed. These are increasing at large deformation and consequently the calculation of the strain hardening rate coefficient is limited at 0.40 true strain. The occurrence of serrations on true stress-strain curves of high manganese austenitic steels is well known. They have been interpreted as dynamic strain aging mechanism or as 'Portevin-Le Chatelier' effect [4,5]. However, the exact nature of the DSA in austenitic steels, i.e. interaction between mobile dislocations and carbon atoms, is not well defined in the literature and is still under discussion [4-6].

A remarkably high strain hardening rate was observed and is displayed in Fig. 1b. The amount of $(\mathrm{d} \sigma / \mathrm{d} \varepsilon) / G_{0}$ is greater than 0.04 up to 0.3 true strain. During the deformation, the strain hardening rate evolves according to different stages. After a pronounced decrease up to $(\mathrm{d} \sigma / \mathrm{d} \varepsilon) / G_{0}=0.045$, from 0 to 0.02 true strain (stage A), the strain hardening rate increases to reach the first constant level $\left((\mathrm{d} \sigma / \mathrm{d} \varepsilon) / G_{0}=0.048\right)$ at 0.1 true strain (stage B). Then, it slightly decreases (stage $C$ ) and reaches the second constant stage at 0.2 true 
Table 1

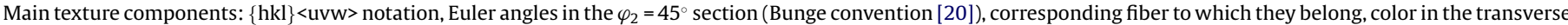

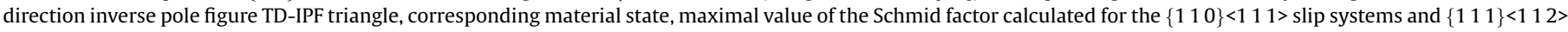
twinning systems.

\begin{tabular}{|c|c|c|c|c|c|c|c|c|}
\hline \multirow[t]{2}{*}{ Symbol } & \multirow[t]{2}{*}{ Texture components } & $\multirow[t]{2}{*}{$ hkl }$<$ uvw $>$ & \multirow[t]{2}{*}{ Euler angles } & \multirow[t]{2}{*}{ Fiber } & \multirow[t]{2}{*}{ Color in the TD-IPF triangle } & \multirow[t]{2}{*}{ Material state } & \multicolumn{2}{|c|}{ Schmid's factor } \\
\hline & & & & & & & Slip & Twinning \\
\hline \multicolumn{9}{|l|}{ 口 } \\
\hline \multicolumn{9}{|c|}{ C } \\
\hline$\theta$ & Copper & $\{112\}<111>$ & $90 / 35.26 / 45$ & $<110>/ / \mathrm{DT}$ & Green & As-received & 0.41 & 0.47 \\
\hline $\multicolumn{9}{|c|}{110}<112>$ \\
\hline & \multicolumn{7}{|l|}{ 然 } & 0.31 \\
\hline \multirow[t]{2}{*}{$\square$} & Rotated Goss & $\{110\}<110>$ & $0 / 90 / 45$ & $<100>/ /$ DT & Red & Deformed & 0.41 & 0.23 \\
\hline & Cube & $\{001\}<100>$ & $45 / 0 / 45$ & $<100>/ /$ DT & Red & Deformed & 0.41 & 0.23 \\
\hline
\end{tabular}

strain $\left((\mathrm{d} \sigma / \mathrm{d} \varepsilon) / G_{0}=0.043\right)$ up to 0.3 true strain (stage D). Finally, over 0.3 true strain, the strain hardening rate decreases again (stage E) up to the specimen rupture. This sustained high level of strain hardening rate, observed up to large strains, confers high strength and ductility to this fine-grained Fe-Mn-C TWIP steel.

\subsection{Texture evolution}

Tensile deformation along the prior sheet transverse direction TD leads to the formation of a sharp texture characterized by four distinct texture components: the $\{110\}<112>$ brass, the $\{112\}<110>$ rotated copper, the $\{110\}<110>$ rotated Goss and the $\{001\}<100>$ cube. Fig. $2 a-d$ shows the $\{100\}$ and $\{111\}$ pole figures and the $\varphi_{2}=45^{\circ}$ ODF sections for the as-received material - as cold rolled and recrystallized - and for the samples deformed at $0.2,0.3$ and 0.55 true strain. The horizontal direction of the pole figures corresponds to the tensile direction.

At 0.55 true strain, the highest orientation densities are reached for the brass component (maximal value of 15) and for the rotated copper component (maximal value of 7.6). The rotated Goss and the cube components are weaker with respectively maximum ODF values of 1.8 and 2.3. On the pole figures, a pronounced density of $\langle 111\rangle$ poles and a lower density of $\langle 100\rangle$ poles are observed. In fact, the major brass and rotated copper components belong to the pronounced $<111>/ /$ TD fiber orientation and the minor rotated Goss and cube components to the weak $<100>/ /$ TD fiber orientation. The main texture components presented in Fig. 2 are listed in Table 1.

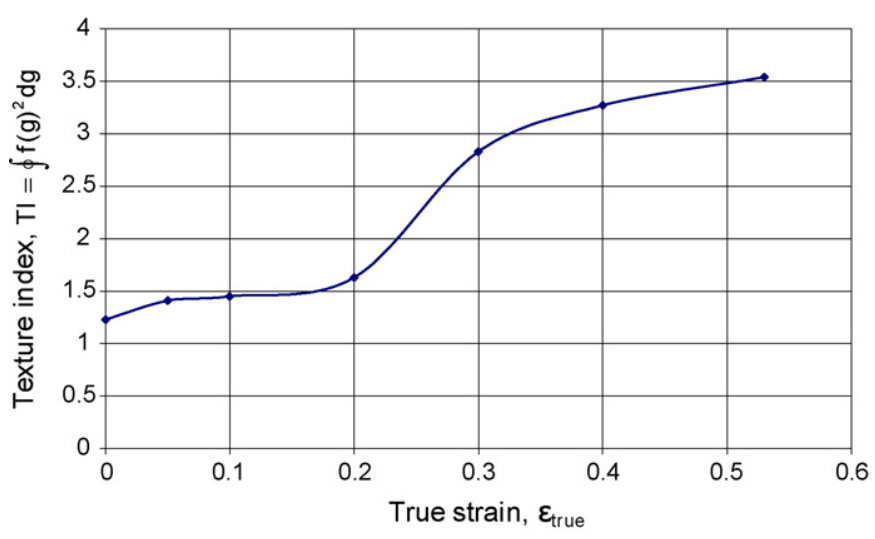

Fig. 3. Evolution of the texture index $\mathrm{TI}=\phi f(g)^{2} \mathrm{~d} g$ as a function of the true strain.
This texture sharpens stepwise as underlined by the evolution of the texture index TI (Fig. 3) and the volume fraction of each texture component (Fig. 4).

Up to 0.2 true strain, the texture remains very weak. The TI is about 1.5 . However, the texture components change significantly during this deformation step. The ODF maximum shifts from the Goss position $\left(90^{\circ}, 90^{\circ}, 45^{\circ}\right)$ to the brass position $\left(55^{\circ}, 90^{\circ}, 45^{\circ}\right)$. The deformation components progressively increase at the expense of the initial Goss and copper components of the as-received material. The volume fraction of grains with brass orientation $(8 \%$ in the asreceived material) enlarges with increasing the deformation.

From 0.2 to 0.3 true strain, the texture significantly sharpens. The $\mathrm{TI}$ increases from 1.5 to about 3 . In this range of deformation, the development of the texture components induced by the deformation is very strong. The increase of the $<111>/ /$ TD fiber is very important in comparison to the one of the $<100>/ /$ TD fiber. At 0.3 true strain, $45 \mathrm{vol} . \%$ of the grains are oriented close to $<111>/ / \mathrm{TD}$ fiber and only 10 vol.\% are close to $<100>/ /$ TD fiber (Fig. 4). Copper and Goss components progressively disappear (corresponding volume fraction in green in Fig. 4).

At 0.3 true strain, the deformation texture is almost fully developed. Beyond this deformation, the TI increases slowly. However, the brass and rotated copper components continue to strengthen, as it can be seen on Fig. 2d. Moreover, new orientations

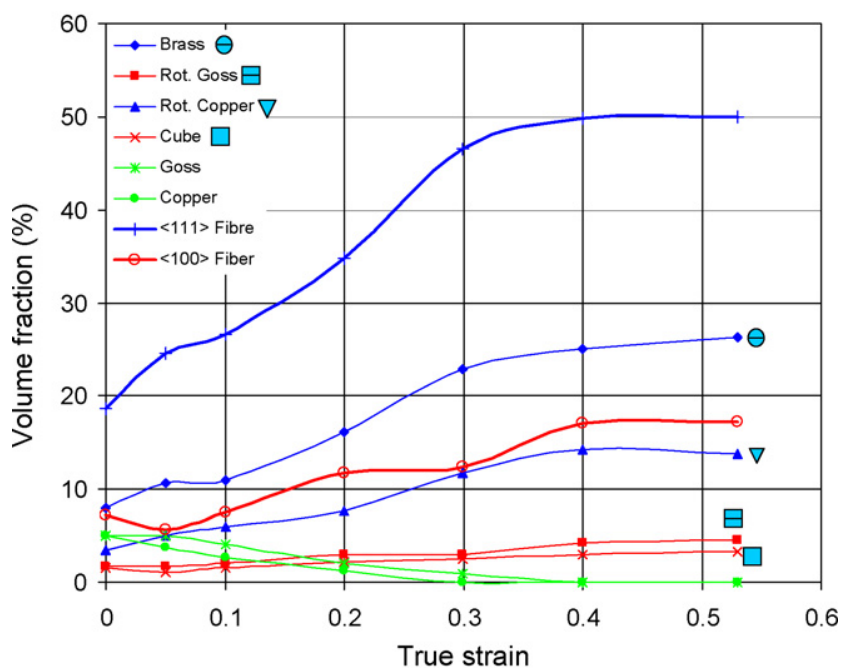

Fig. 4. Evolution of the volume fraction of the main texture components (considering $10^{\circ}$ of tolerance) as a function of the true strain. The data are calculated from the ODF. 


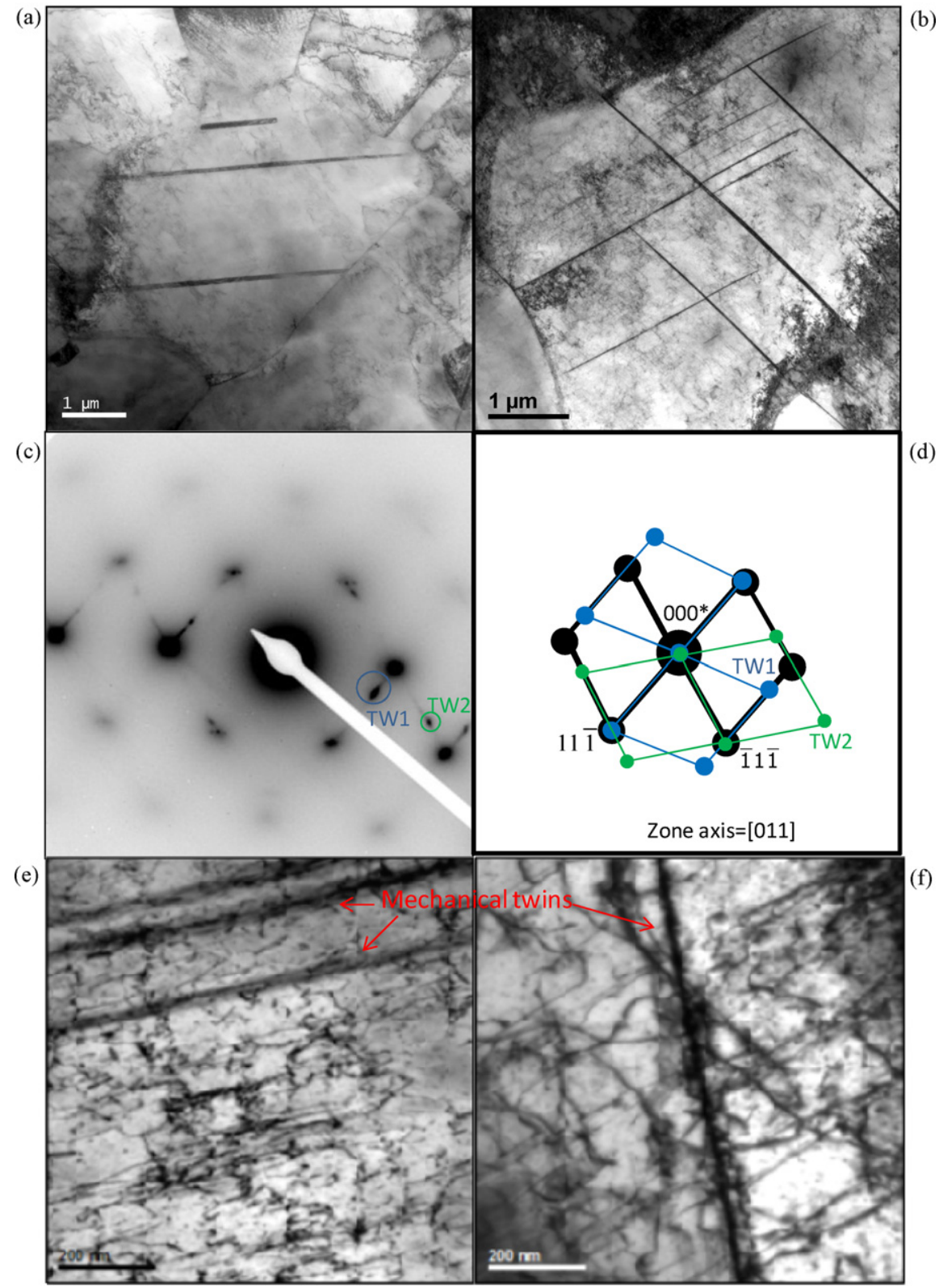

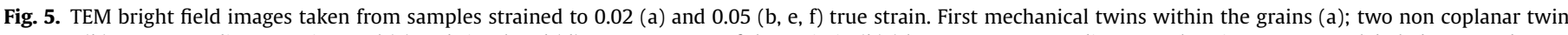

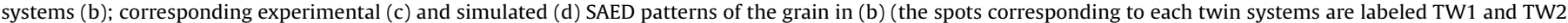

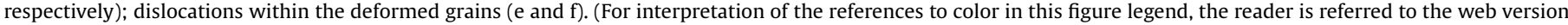
of the article.)

are generated by mechanical twinning, which may influence the texture evolution. This point will be discussed in Section 4 .

\subsection{Microstructure analysis}

\subsubsection{Low strain regions $(\varepsilon \leq 0.1)$}

In the first steps of the deformation, the grains show twins in addition to numerous dislocations. The twinning activity depends more on the grain size than on the grain orientation.

Primary twins were observed in the samples strained at 0.02 true strain as illustrated in TEM micrographs of Fig. 5a. Thus the onset of twinning coincides with the increase of strain hardening rate at 0.02 true strain. Some grains have already activated two twin systems, see Fig. 5b. The corresponding selected area electron diffraction (SAED) and indexed patterns are shown in Fig. 5c and $\mathrm{d}$. In order to improve the bright field contrast and better see the twins, the sample has been tilted a few degrees off the [0 011$]$ zone axis. This is the reason why the diffracted intensities are not homogenously distributed. This SAED pattern gives evidence of the existence of two different twin systems. The first one, formed on the (11 $\overline{1}$ ) plane, induces the diffraction spots represented in blue in Fig. $5 \mathrm{~d}$. The blue network is obtained by a $180^{\circ}$ rotation of the matrix reciprocal lattice around the $[11 \overline{1}]^{*}$ reciprocal direction. A similar construction with $[\overline{1} 1 \overline{1}]^{*}$ direction allows the identification of the diffraction spots associated with the twins on the $(\overline{1} 1 \overline{1})$ plane. On the SAED pattern of Fig. $5 \mathrm{c}$, the spots corresponding to each twin systems are labeled TW1 and TW2, respectively. The twin thickness is about $10-40 \mathrm{~nm}$. For these low deformations levels, the grains also present numerous dislocation densities (see Fig. 5e,f).

Fig. 6 shows the results of the EBSD analysis performed on the sample strained at 0.1 true strain. The twin thickness is smaller than the resolution of the EBSD map performed with a step of $60 \mathrm{~nm}$. 

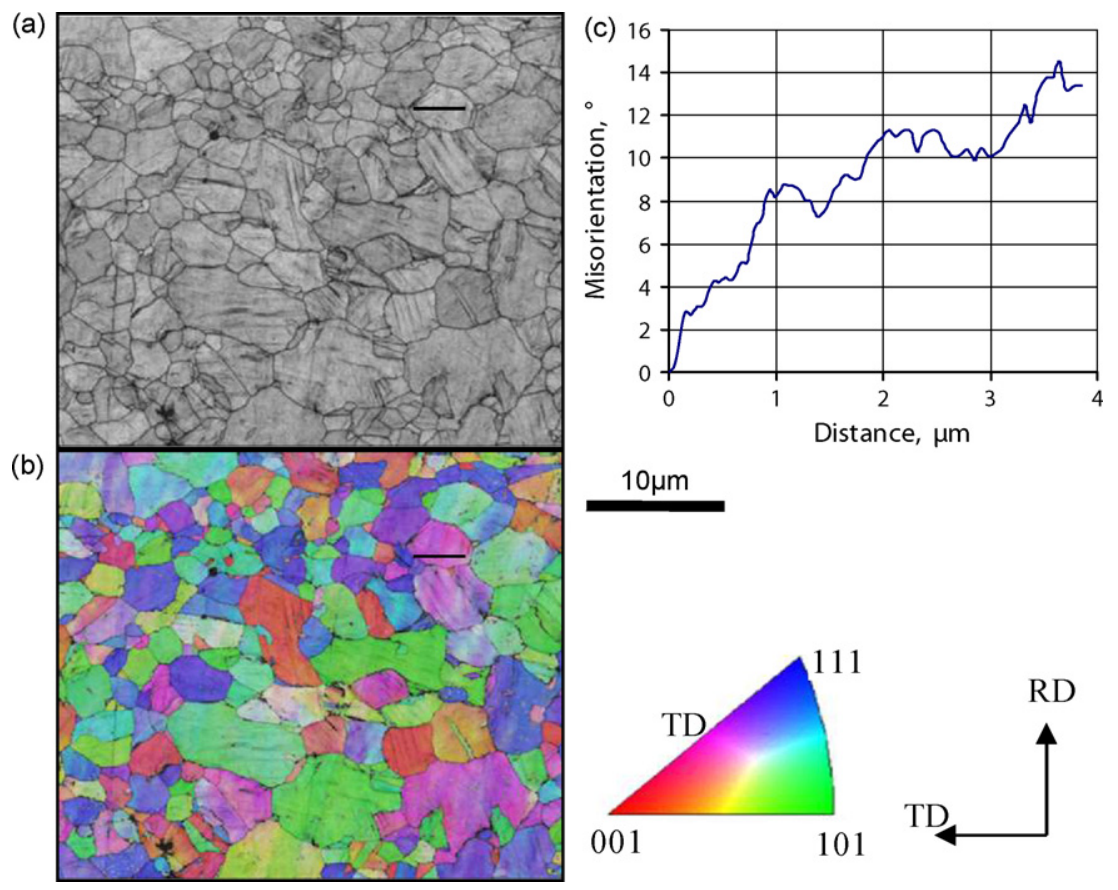

Fig. 6. EBSD maps of sample strained to 0.1 true strain. KPQ map (a). TD-IPF map (b). Misorientation profile along the black line of figure (a) (c).

Their orientations cannot be measured by automated EBSD analysis. However, the Kikuchi pattern quality (KPQ) map reveals the presence of straight dark lines within some grains in Fig. 6a. We checked that these low KPQ values are due to two patterns overlapping (twin and matrix). Thus, these lines reveal the deformation twins. Half of the grains present one visible twinning system.

The TD inverse pole figure map of Fig. 6b confirms the weak texture previously observed in Fig. 2. The activated strain mechanisms and the related grain rotations depend on the grain size and its initial orientation. For example, the larger grains close to the Goss and copper orientations, in green in Fig. 6b, preferentially activate twins. These grains, which were already observed in the as-received material, are indeed well oriented for twinning according to the Schmid factor as depicted in Table 1. With increasing strain, these grains rotate towards the deformation components and finally the Goss and copper components disappear at 0.3 true strain as displayed in Fig. 4. The orientations corresponding to the $<111>/ /$ TD and $<100>/ /$ TD fibers (blue and red colored grains on Fig. $6 \mathrm{~b}$, respectively), appear during deformation by dislocation glides. In addition, twins are also observed in these larger grains.

The intra-granular misorientations resulting from the deformation were analyzed. At 0.1 true strain, about $10 \%$ of the grains have an internal orientation spread larger than $5^{\circ}$. The cumulative misorientation profile along a line has also been drawn for different grains. Fig. $6 \mathrm{c}$ presents the profile along the thick black line in Fig. 6b. Over a distance of $4 \mu \mathrm{m}$, the cumulated misorientation reaches $12^{\circ}$ (up to $20^{\circ}$ in some grains). However, the misorientation between adjacent pixels does not exceed $1^{\circ}$. Such intra-granular misorientations are associated to the formation of dislocations which assure the plastic strain compatibility between neighboring grains and accommodate the deformation gradients [21,22].

\subsubsection{Medium strain regions $(0.1 \leq \varepsilon \leq 0.3)$}

Between 0.2 and 0.3 true strain significant changes in the twinning activity are observed along with the texture evolution. The main microstructural features are the formation of different twin configurations with the occurrence of secondary twin systems in most of the grains, the strong interaction between grain orientation (a)

(b)
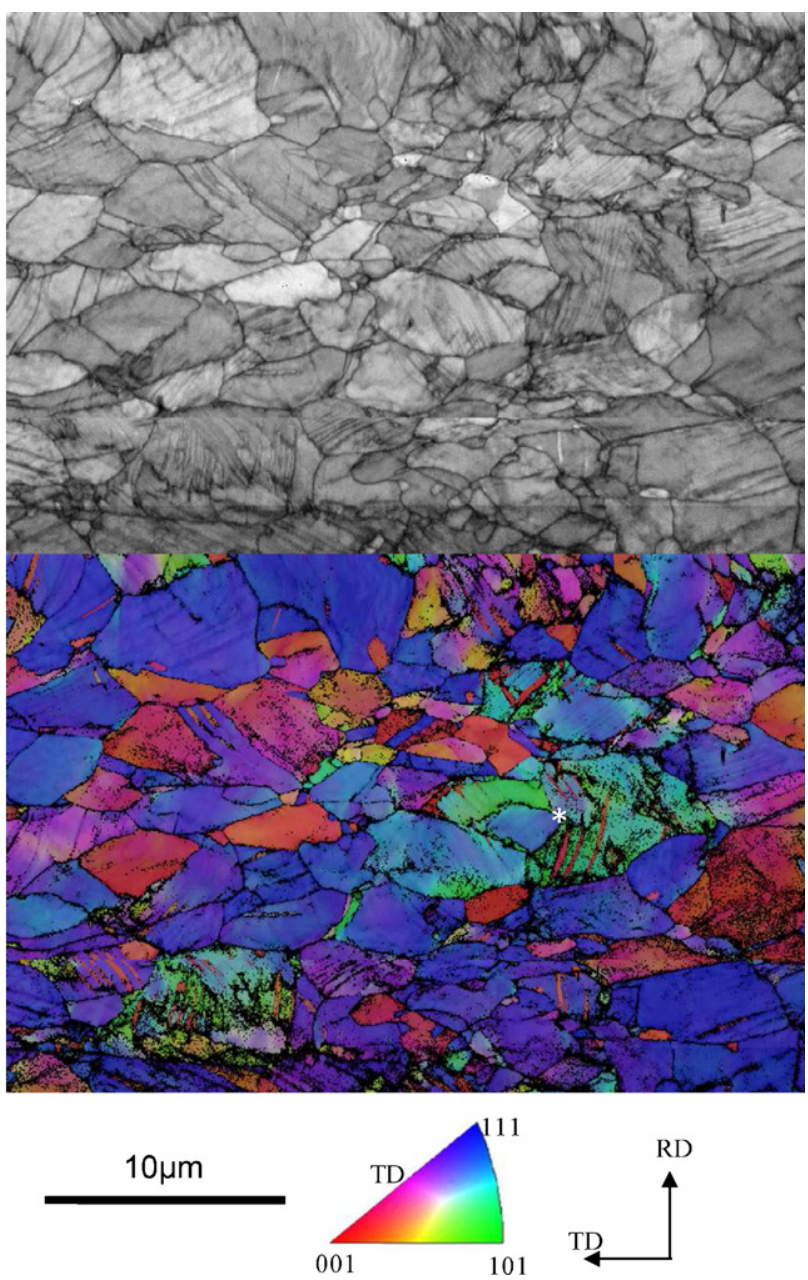

Fig. 7. EBSD maps of a strained sample to 0.3 true strain. KPQ map (a). TD-IPF map (b). 

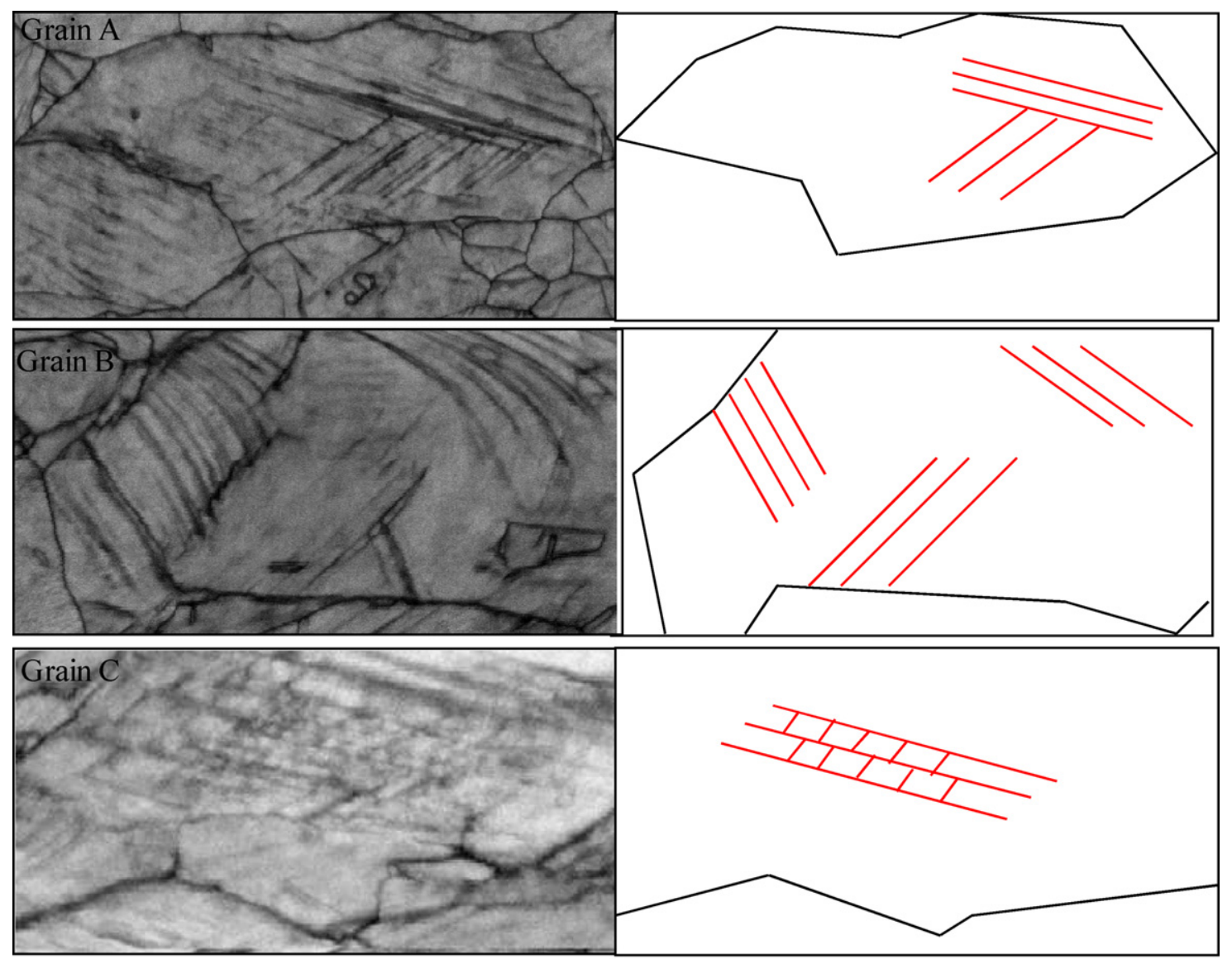

$5 \mu \mathrm{m}$

Fig. 8. KPQ maps of specific grains highlighting different twin configurations-sample strained to 0.2 true strain.

and twinning activity and the development of high misorientation boundaries within the grains.

TEM analysis shows that twins are organized in bundles. With increasing deformation, the number of twins in bundles increases and the twin thickness remains constant. Fig. 7 presents a typical EBSD map of a sample strained at 0.3 true strain. As the twin density in each bundle has increased, it is possible to measure the twin orientations by automated EBSD analysis. In fact, the twin orientation becomes major in the probed volume. But the twin thickness deduced by EBSD is overestimated. The austenitic matrix between the twins cannot be differentiated. The maximum thickness of the twin bundles is about $250 \mathrm{~nm}$.

In this range of deformation, the number of grains with a secondary twinning system significantly increases, as shown in the EBSD KPQ maps. Fig. 8 illustrates the three main configurations observed in a sample deformed at 0.2 true strain. In grain $A$, the twinning systems were simultaneously activated. In grain B, two systems were activated in different regions of the grain. In grain $C$, they were sequentially activated. Similar twin configurations were found in a sheet having an average grain size of $20 \mu \mathrm{m}$ [13].

The texture evolution and its strengthening around the main texture components, described in Section 3.2, is clearly revealed by the TD-IPF map in Fig. 7b. The majority of grains are blue indicating that they are misoriented by less than $20^{\circ}$ from the $<111>/ /$ TD fiber including the brass and rotated copper components. A strong interaction between grain orientation and twinning activity is observed. Grains from the $<111>/ /$ TD fiber exhibit a higher fraction of deformation twins than grains belonging to the $<100>/ /$ TD fiber. A small volume fraction of grains exhibits the copper and Goss components ( $<110>/ /$ TD fiber) and has a well developed twin microstructure.

Another feature is the development of medium to high angle boundaries within some deformed grains. This is illustrated by the green/blue colored grain in Fig. 9 (after 0.3 true strain, marked by a white star in Fig. 7). The KPQ map of Fig. 9a reveals the development of sub-boundaries within the grain. The misorientation across these sub-boundaries is about $10^{\circ}$. The sub-boundaries seem to delimit different twin bundles as shown in Fig. 9b. This leads to the grain fragmentation. The sub-grains gradually rotate towards the deformation components and could be considered as new grains after a certain amount of deformation. The decrease in the indexing rate to $75-80 \%$ is caused by the strong lattice distortions and the increase of the boundaries density and broadening. The intra-granular misorientations are also increasing. About $50 \%$ of the grains have an IOS greater than $5^{\circ}$ (most of these grains have an IOS between $5^{\circ}$ and $10^{\circ}$ ). This IOS is due to the formation of highly misoriented sub-boundaries and to the dislocation densities leading to the elastic lattice distortion.

\subsubsection{Large strain regions including rupture $(0.3 \leq \varepsilon \leq 0.55)$}

In the final deformation step, the volume fraction of twins still increases. However, the overall twin volume fraction remains low and the twin orientations represent a small contribution to the macroscopic texture. Large regions with numerous dislocation accumulations develop within the grains. These features are illustrated in the EBSD maps of Fig. 10 of the strained sample at 0.4 true strain. 
(a)
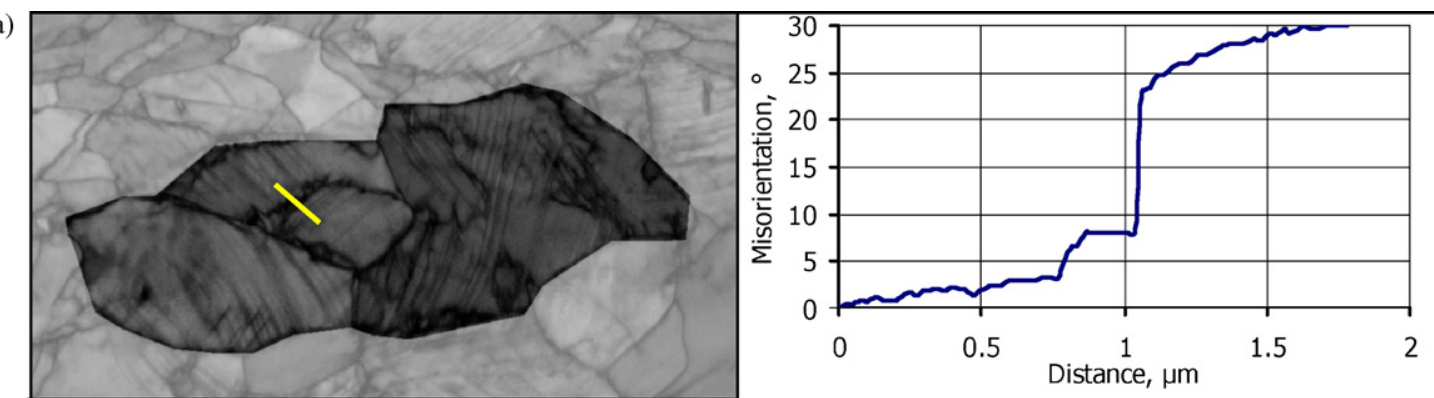

(b)

(c)
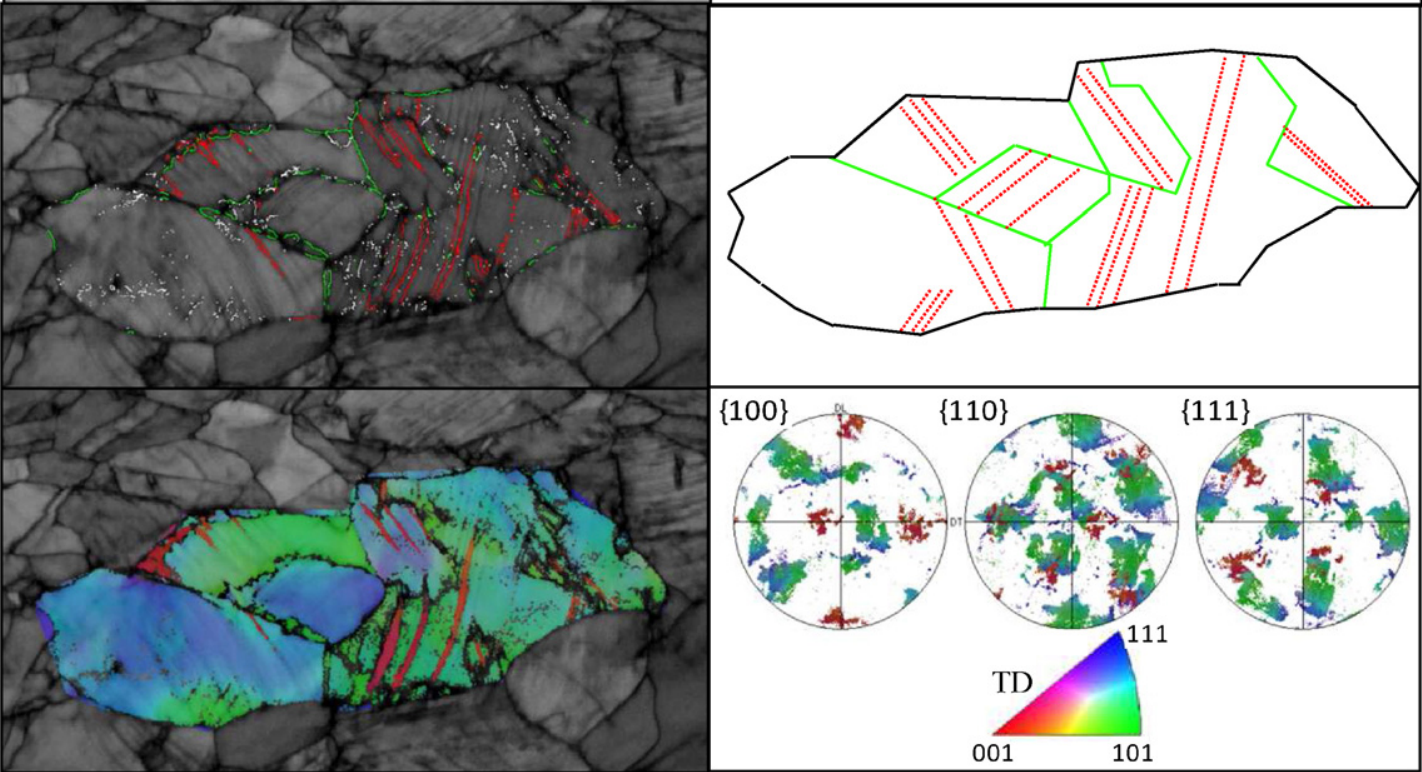

Fig. 9. EBSD representations related to the grain marked by the white star in Fig. 7; KQP map with the misorientation profile along the yellow line (a); KPQ map with specific misorientation lines and corresponding schematic drawings: twin boundaries in red-grain boundaries misoriented by less than $3^{\circ}$ in white and less than $10^{\circ}$ in green (b); TD-IPF map with the corresponding $\{100\},\{110\}$ and $\{111\}$ pole figures (c). (For interpretation of the references to color in this figure legend, the reader is referred to the web version of the article.)

Beyond a strain of 0.3 true strain, new deformation twins are formed within the grains. The KPQ maps of the Figs. 7a and 10a are showing evidence of an increase in the twinning activity for strains from 0.3 to 0.4 . The number of twins in the bundles increases leading to thicker bundles and therefore to larger volume fractions of twins. These bundles are about $500 \mathrm{~nm}$ large in some cases. On the EBSD map, these appear as large twinned domains.

At this deformation level, most of the grains are oriented close to the texture components as shown in Fig. 10b. The grains with orientations close to the initial Goss and copper components have disappeared. The ODF shows an orientation density increase around the brass and rotated copper components. The strong relation between the grain orientation and the twinning activity is still observed. Grains of the $<111>/ /$ TD fiber exhibit a larger volume fraction of twins than those of the $<100>/ /$ TD fiber.

On the sample strained to 0.4 , the twin bundles are large enough to measure the twin orientations. Twins formed in the $<111>/$ /TD oriented grains reinforce the $<100>/ /$ TD fiber whereas twins within the $<100>/ /$ TD oriented grains create orientations in the $<111>/ /$ TD fiber. The strict twin orientations generated by each main texture component have been calculated. Fig. 11(a-d) shows in the ODF section at $\varphi_{2}=45^{\circ}$ the twin orientations that are related to the largest Schmid factor. These twins are correspondingly observed on the EBSD map. The twin and grain orientations do not overlap. The same calculation has been performed considering a set of grain orientations dispersed around the ideal texture component as presented in Fig. 11e and f. In this case, the deformed grain and twin orientations overlap. It can be deduced that no new texture component appears by twinning. The EBSD map indicates that the volume fraction of grains oriented close to $<100>/ /$ TD fiber decreases slightly from 0.3 to 0.4 true strain, see Figs. 7 and 10 . XRD data indicate the volume fractions of these orientations increase as shown in Fig. 4. This evolution results from the increase of the twin volume fraction in grains oriented close to $\langle 111>/ /$ TD fiber. This aspect is detailed in Section 4 where the volume fraction of twins will be evaluated.

The EBSD map Fig. 10b reveals large intra- and inter-granular areas where no diffraction patterns were indexed. These correspond to sets of pixels with very low KPQ index appearing in dark grey color in Fig. 10a. The decrease of the indexing rate to $70 \%$ is correlated with the development of high deformation regions which could not be indexed because of the strong lattice distortion induced by accumulation of dislocations densities. As interpreted by Allain [14], this indicates a pronounce localization of deformation such as local necking which causes the failure of the tensile sample.

\section{Discussion}

\subsection{Analysis of the texture evolution: interaction with twinning}

Tensile testing along the TD generates a sharp austenitic texture in the fine-grained Fe-Mn-C TWIP steel. This deformation texture is characterized by four components: the $\{110\}<112>$ brass, the 


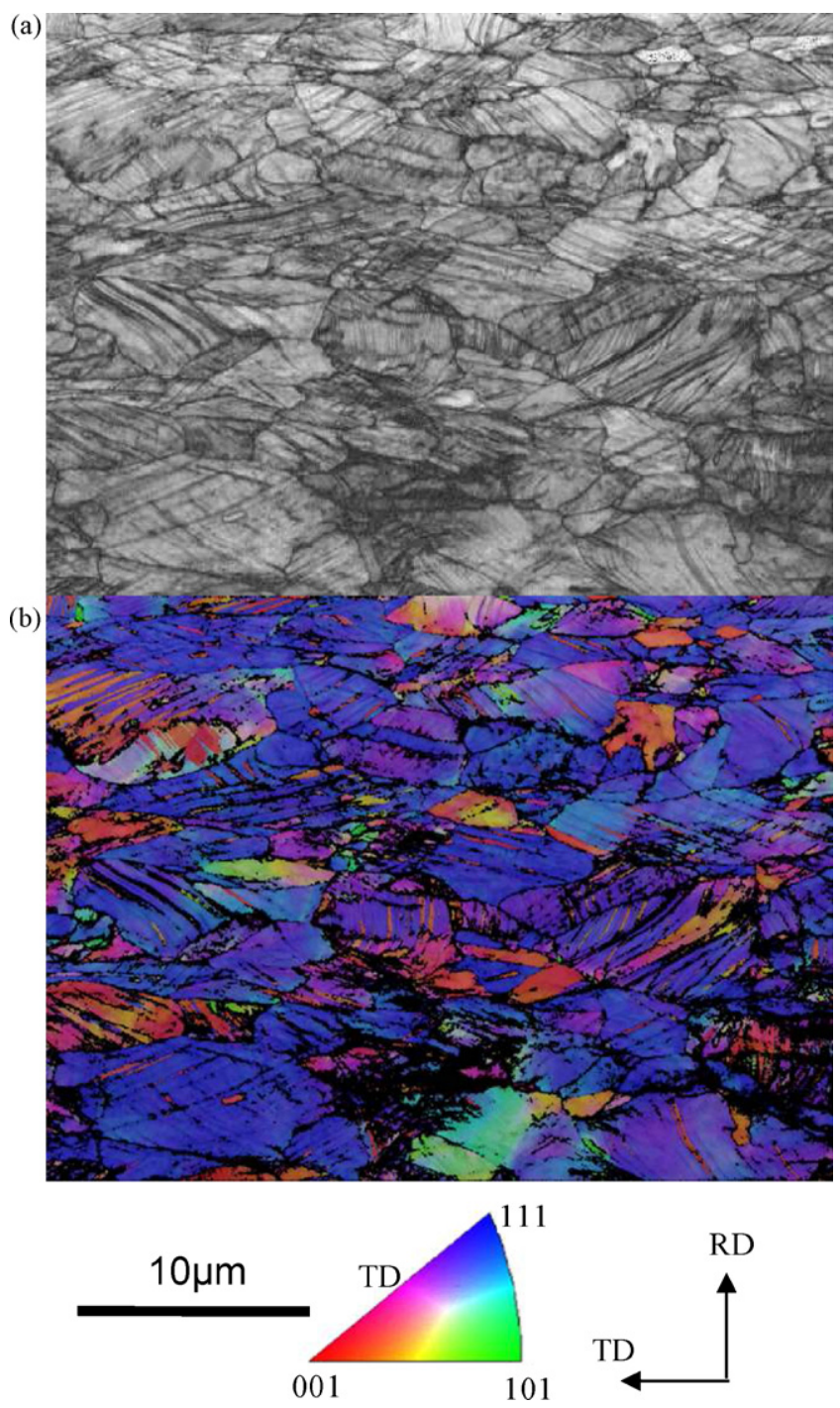

Fig. 10. EBSD maps of a strained sample to 0.4 true strain. KPQ map (a). TD-IPF map (b).

$\{112\}<110>$ rotated copper, the $\{110\}<110>$ rotated Goss and the $\left\{\begin{array}{lll}0 & 0 & 1\end{array}\right\}<1 \quad 00>$ cube. These components belong either to the pronounced $<111>/ /$ TD fiber (brass and rotated copper) or to the weak $<100>/ /$ TD fiber (rotated Goss and cube) as shown in Figs. 2 and 4. Similar densities of $\langle 111\rangle$ and $\langle 100\rangle$ poles in the tensile direction have been observed on TWIP steels [17] or more generally on austenitic steels with low SFE $[23,24]$. The densities of these components increase by specific grain rotations related to the slip activity. In TWIP steels the occurrence of twinning influences the slip activity, which may modify the volume fraction of the different texture components. This was shown by simulation of texture evolutions with or without taking twinning into account [25].

In the present work, the texture of the as-received TWIP steel was rather weak with grain orientations spread around the Goss and copper texture components. Reinforcement of these orientation densities is not favored by deformation and consequently large grain rotations are required to develop the final texture components. At 0.2 true strain, the main characteristics of the initial texture components disappear without any significant texture strengthening. At 0.3 true strain, the major $<111>/ /$ TD fiber is reinforced, whereas the other texture components show a moderate increase. Further deformation up to 0.55 causes an intensification of the texture components.
The analysis of EBSD data shows that this texture evolution strongly influences the twinning activity. This influence obviously occurs at two steps of deformation. Twins appear in the first deformation stage, see Figs. 5 and 6 . Initial twinning activity in this fine-grained steel is related to the large grain size distribution and to the Goss and copper orientations which belong to the weak initial texture components. These orientations are in fact favorable for twinning, see the Schmid factor values in Table 1. With increasing deformation the development of the major $<111>/ /$ TD fiber still promotes twinning as illustrated in Fig. 10. In fact, the main $<111>/ /$ TD fiber is well suited for twinning (Schmid factor $^{\text {twin }}=0.31$ and Schmid factorslip $=0.27$, see Table 1$)$ while the weak $<100>/ /$ TD fiber is adequate to slip (Schmid factor ${ }^{\text {slip }}=0.41$ and Schmid factor ${ }^{\text {twin }}=0.23$ ). The volume fraction of grains of the $<111>/ /$ TD fiber steadily increases during the deformation, as shown in Fig. 4 . At 0.3 true strain, the majority of grains belongs to the $<111>/ /$ TD fiber. The intensity increase of the main texture components promotes the twinning activity for strains between 0.3 and 0.4 as illustrated in Figs. 7 and 10 in conformity with ref. [17].

However, twinning generates new orientations and may modify the texture and its evolution. After a strain of 0.3 , the twin density in bundles is large enough so that the twin orientations can be measured by using EBSD. The results are showed in Figs. 7 and 10. Due to the spread of the experimental orientations around the texture components, grain and twin orientations often overlap. Twins formed within the $<110>/ /$ TD oriented grains (at low deformation levels) or within the $<111>/ /$ TD oriented grains (at intermediate and high deformation levels) reinforced the $<100>/ /$ TD fiber. The limited number of twins formed within the grain of the $<100>/ /$ TD fiber orientation reinforces the $<111>/ /$ TD fiber. As a consequence, no new texture components are generated by twinning.

As a matter of fact, the analysis of XRD and EBSD data indicates that the contribution of twin orientations to the texture evolution is limited. XRD data show that the volume fraction of grains and twins oriented in $<100>/ /$ TD fiber slightly increases for strains in the range from 0.3 to 0.4 , as shown in Fig. 4 . Besides that the volume fraction estimated from EBSD of the individual grains decreases. The difference between both approaches suggests that the overall increase of this texture component is mainly related to twinning. Several authors report a small influence of twinning on the texture evolution [26-28]. In these studies the volume fraction of twins generated during deformation in tension parallel to TD is not sufficient to significantly influence the texture.

The volume fraction of twins is an important parameter to understand the mechanical behavior - plasticity and strain hardening rate - of TWIP steels. However, it is difficult to estimate. The study of the literature shows that several authors have tried to quantify the twin volume fraction in low SFE fcc materials by optical microscopy $[3,11,13]$ by using morphological criteria [29]. Such an evaluation only gives an estimation of the twin volume fraction.

In the present work the twin volume fraction is estimated by discerning the contributions of the grains and twins in the ODF thanks to the EBSD maps.

The EBSD analysis showed that most of the twins are oriented close to the $<100>/ /$ TD fiber with certain spread, see Figs. 10 and 11. However, the determination of the overall twin volume fraction is not directly possible. The volume fraction of the deformed grains of this fiber can be determined from EBSD measurements whereas the total volume fraction of twins and grains belonging to this fiber are obtained from the ODF via XRD measurements.

Thus, the difference $(\Delta)$ between these two volume fractions corresponds to the volume fraction of twins. $\Delta$ increases from $6 \%$ to $9 \%$ between 0.4 and 0.55 true strain, respectively. These values are in agreement with the twin volume fraction estimated by 

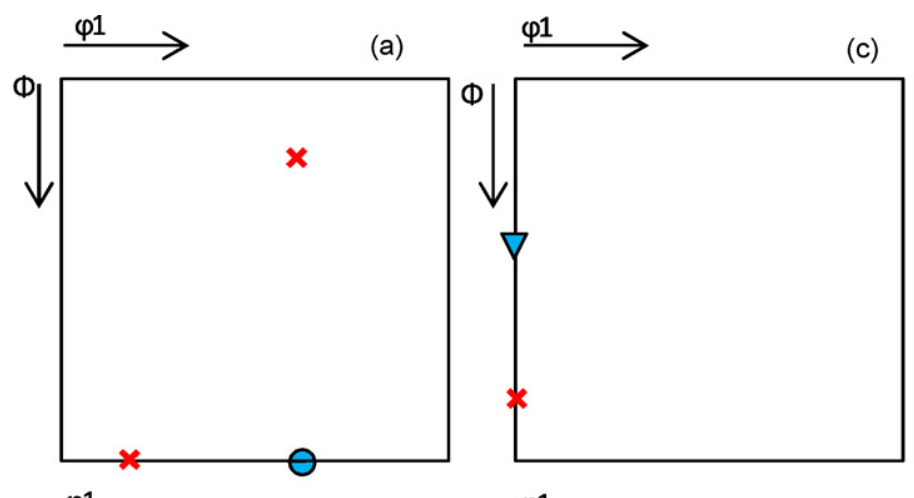

$\underline{\varphi 1}$
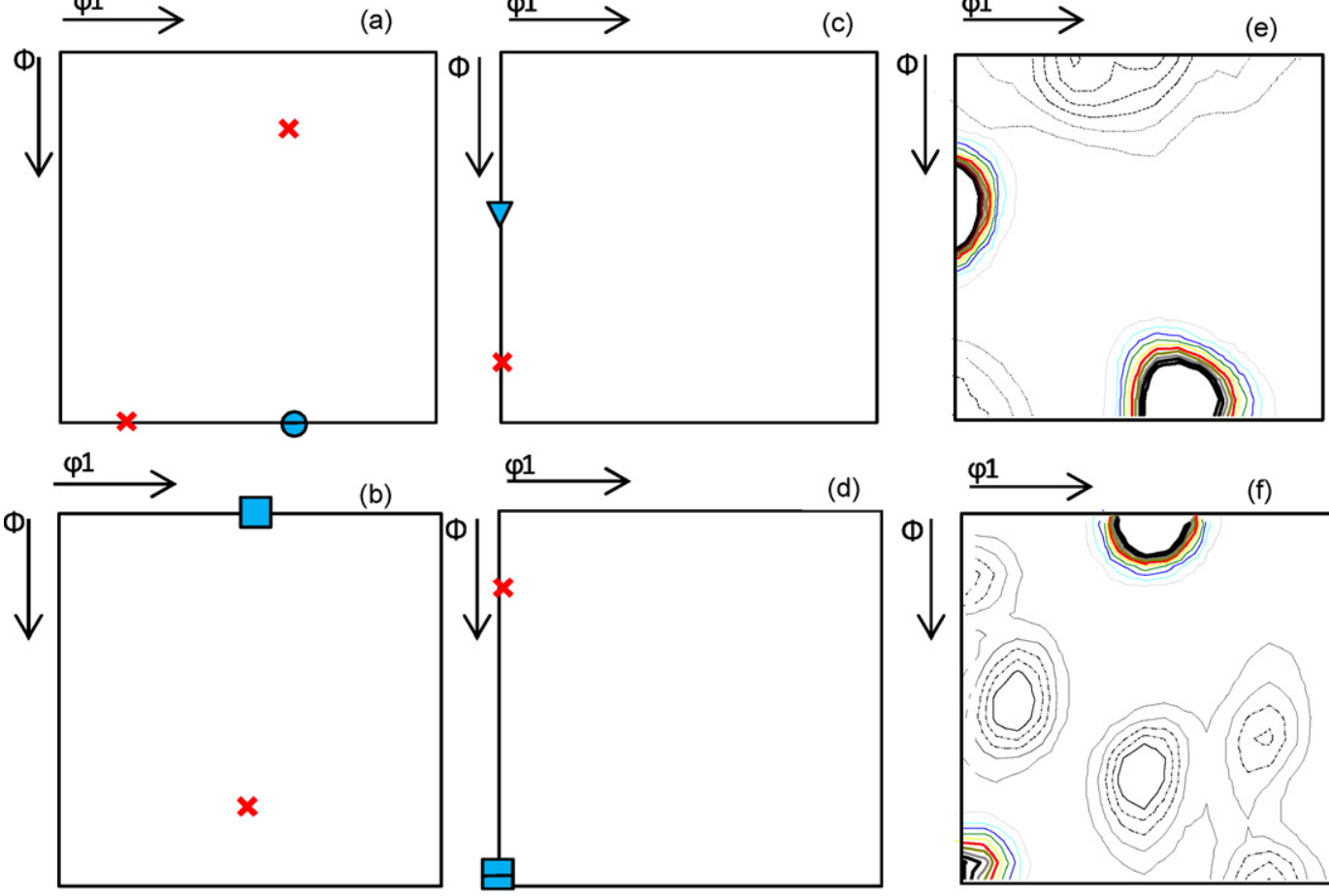

$\underline{\varphi 1}$

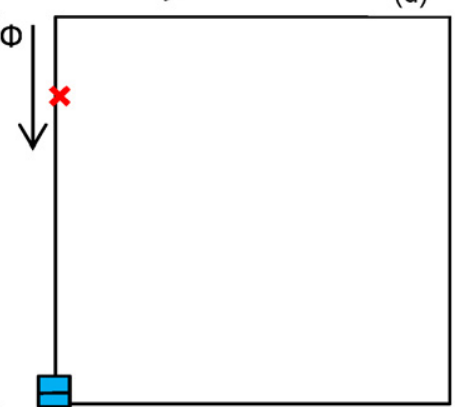

(d)

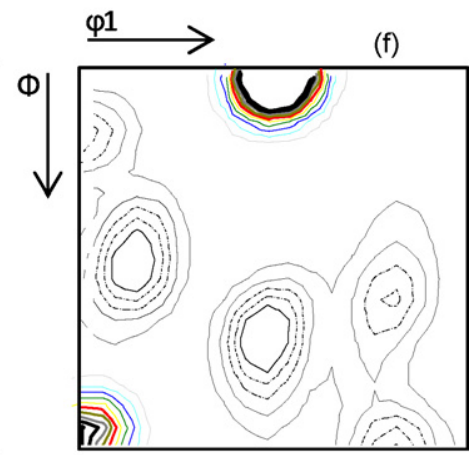

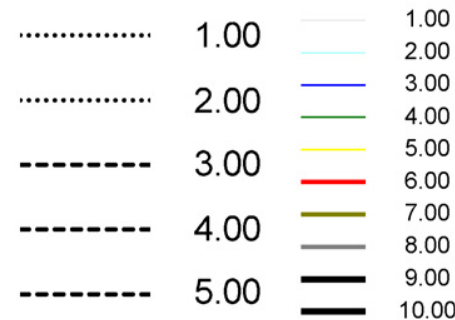

Fig. 11. Calculated twin and parent orientations represented in the ODF section at $\varphi_{2}=45^{\circ}$. For each parent orientation only one or two twin orientations associated to the

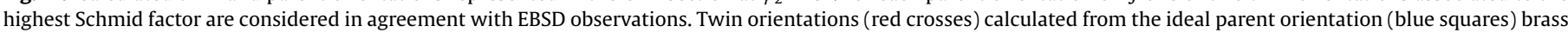

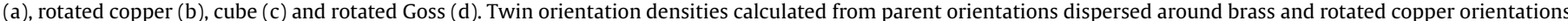

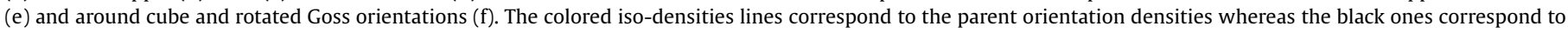
the twin orientations. (For interpretation of the references to color in this figure legend, the reader is referred to the web version of the article.)

Allain $[13,14]$ for a coarse-grained TWIP steel of the same chemical composition.

\subsection{Microstructure evolution-influence on the strain hardening rate}

TEM investigations show that the transition from stage A to stage $B$ corresponds to the onset of twinning within grains deformed by multi-slip which is considered as necessary to form twins [30]. For this fine-grained steel, the required macroscopic stress for the onset of twinning is about $550 \mathrm{MPa}$ and is reached at 0.02 true strain, see Fig. 1. Specific texture components of the weak initial texture are well suited for mechanical twinning. The onset of twinning causes an increase in strain hardening rate that reaches a plateau at 0.05 up to 0.1 true strain. The twins even in low volume fraction may reduce the effective grain size and act as strong obstacles for dislocation motions. In other low SFE materials, like MP35N (nickel-cobaltbased alloy) or $\alpha$-brass [3,31-33], stage B is characterized by a uniform constant strain hardening rate. However, Rémy [11,12] and Mahajan and Chin [34] consider that twin-slip interactions increase the strain hardening rate. A similar increase corresponding to the onset of twinning was also observed in high purity alpha-titanium [35].
From 0.1 to 0.2 true strain, a weak decrease of the strain hardening rate occurs corresponding to stage $C$. In this range of deformation, twinning is less active as before. The texture remains very smooth. Grains exhibiting the Goss and copper orientations vanish between 0.1 and 0.2 true strain as illustrated in Fig. 4. In those grains the dislocations start to be accumulated and form sub-boundaries. In some grains, these sub-boundaries delimit twin bundles. This rearrangement of dislocations and the slowing down of twinning activity may be at the origin of the weak decrease of strain hardening rate. Asgari et al. [3] also suggest that the decrease of the strain hardening rate in low SFE fcc materials is related to the inhibition of twin formation. The twins generated in the initial stage of deformation will decrease the grain size and are acting as obstacles for twinning [36,37].

A constant strain hardening rate occur between 0.2 and 0.3 true strain (stage D). This is concomitant with two microstructural features. At 0.2 true strain the texture strengthens around the main brass and rotated copper components ( $<111>/ /$ TD fiber) and the weak rotated Goss and cube components ( $<100>/ /$ TD fiber). The number of grains with the $<111>/ /$ TD fiber orientation is continuously increasing as shown in Fig. 4. Those grains are more adequate for twinning than those belonging to the $\langle 100\rangle / /$ TD fiber orientation, see Table 1 . As the first twins have reduced the grain size a 
higher stress is necessary to generate new twins. For higher strains, a large number of grains exhibit a second twinning system. The formation of secondary twins reduces even more the mean free path of dislocations. These mechanisms maintain the strain hardening rate on a high level.

Finally, from 0.3 true strain to rupture, even if the twin volume fraction increases significantly, the strain hardening rate continuously decreases (stage E). The twin bundles become denser and thicker. Large intra- and inter-granular regions with numerous dislocation accumulations are developed, indicating a pronounced localization of the deformation which consequently tends to the sample failure.

\section{Conclusion}

The tensile behavior of a fine-grained Fe-22Mn-0.6C TWIP steel with an average grain size of $2.6 \mu \mathrm{m}$ has been analyzed with respect to texture and microstructure evolutions. The strong interaction between crystallographic slip, mechanical twinning and texture components is described and discussed for subsequent deformation steps.

Tensile testing along the TD produces a sharp texture with a pronounced $<111>/ /$ TD fiber and a weak $<100>/ /$ TD fiber, respectively. The deformation is accommodated by crystallographic slip and mechanical twinning. This provokes variations in the microstructure and consequently in the texture.

- Primary twins occur due to the presence of Goss and copper orientations of the weak initial texture. Twins are activated in the first stage of deformation at about 0.02 true strain and $550 \mathrm{MPa}$. It is shown that with increasing deformation the development of the main $<111>/ /$ TD fiber which is well suited for twinning reinforces the twinning activity.

- Moreover, the deformation twins developed in grains having orientations close to the two main texture components $-<111>/ / \mathrm{TD}$ and $<100>/ /$ TD fibers - generate orientations close to those orientations. Thus, mechanical twinning does not create additional orientations but increase slightly the density of the existing orientations.

A method to determine the volume fraction of the twins has been developed. This combines the global ODFs, determined by $X R D$, and microstructural information provided by EBSD. A true strain of 0.55 produced a volume fraction of twins estimated to be $9 \%$.

\section{Acknowledgments}

The authors acknowledge gratefully ArcelorMittal Research SA for financial and technical support and for providing the material.
The authors would also acknowledge Dr. B. Bolle (LETAM UMR CNRS 7078 University Paul Verlaine of Metz) for the XRD measurements, Region Lorraine and CNRS for financial support and the research team 'Material Forming' leading by Dr. V. Favier for fruitful discussions.

\section{References}

[1] O. Grassel, L. Kruger, G. Frommeyer, L.W. Meyer, Int. J. Plasticity 16 (2000) 1391-1409.

[2] C. Scott, N. Guelton, S. Allain, M. Farral, P. Cugy, Proceeding of the MS\&T'05 Conference (2005), Pittsburgh, PA, USA, 2005.

[3] S. Asgari, E. El-Dabaf, S.R. Kalidindi, R.D. Doherty, Metall. Mater. Trans. A 28A (1997) 1781-1795.

[4] Y.N. Dastur, W.C. Leslie, Metall. Mater. Trans. A 12A (1981) 749-759.

[5] P.H. Adler, G.B. Olson, W.S. Owen, Metall. Mater. Trans. A 17A (1986) 17251737.

[6] L.H. De Almeida, I. Le May, P.R.O. Emygdio, Mater. Charact. 41 (1998) 137150.

[7] B. Hutchinson, N. Ridley, Scripta Mater. 55 (2006) 299-302.

[8] T.S. Shun, C.M. Wan, J.G. Byrne, Acta Metall. Mater. 40 (1992) 3407-3412.

[9] L. Bracke, J. Penning, N. Akdut, Metall. Mater. Trans. A 38A (2007) 520-528.

[10] I. Karaman, A. Sehitoglu, A.J. Beaudoin, Y.I. Chumlyakov, H.J. Maier, C.N. Tomé, Acta Mater. 41 (2000) 2031-2047.

[11] L. Rémy, Acta Metall. 26 (1978) 443-451.

[12] L. Rémy, Metall. Mater. Trans. A 12A (1981) 387-408.

[13] S. Allain, J.P. Chateau, O. Bouaziz, M. Legros, X. Garat, Proceeding of the International Conference on TRIP-Aided High Strength Ferrous Alloys (2002), Ghent, Belgium, 2002

[14] S. Allain, Ph.D. thesis, 2004, INPL, France.

[15] O. Bouaziz, S. Allain, C. Scott, Scripta Mater. 58 (2008) 484-487.

[16] S. Vercammen, B. Blanpain, B.C. De Cooman, P. Wollants, Acta Mater. 52 (2004) 2005-2012.

[17] P. Yang, P. Xie, L. Meng, H. Ding, Z. Tang, Scripta Mater. 55 (2006) 629-631.

[18] S. Allain, J.P. Chateau, O. Bouaziz, S. Migot, N. Guelton, Mater. Sci. Eng. A-Struct. 387 (2004) 158-162.

[19] R.A. Schwarzer, Texture Microstruct. 20 (1993).

[20] H.J. Bunge, Texture Analysis in Material Science, DGM, 1982.

[21] K. Verbeken, L. Kestens, Mater. Sci. Forum 408 (2002) 559-564.

[22] D. Jorge-Badiola, A. Iza-Mendia, I. Gutiérrez, J. Microsc.-Oxford 228 (2007) 373-383.

[23] B. Petit, N. Gey, M. Cherkaoui, B. Bolle, M. Humbert, Int. J. Plasticity 23 (2007) 323-341.

[24] R. Kubler, K. Inal, M. Cherkaoui, M. Berveiller, J. Eng. Mater. Technol. 125 (2003) 12-17.

[25] D. Barbier, N. Gey, B. Bolle, M. Humbert, S. Allain, Proceeding of Materiaux 2006 Dijon, France, 2006.

[26] T. Leffers, J.B. Bildsorensen, Acta Metall. Mater. 28 (1990) 1917-1926.

[27] L. Leffers, Proceeding of ICOTOM 11, International Academic Publishers, 1996 pp. 299-306.

[28] B.J. Duggan, W.B. Hutchinson, M. Hatherly, Scripta Metall. 12 (1978) 293 295.

[29] R.L. Fullman, Trans. AIME 197 (1953) 447-452.

[30] F.R.N. Nabarro, Dislocations in Solids, vol. 9, Elsevier Science, Amsterdam, 1992

[31] E. El-Danaf, S.R. Kalidindi, R.D. Doherty, Metall. Mater. Trans. A 30A (1999) 1223-1233.

[32] S.R. Kalidindi, Int. J. Plasticity 14 (1998) 1265-1277.

[33] S.R. Kalidindi, Int. J. Plasticity 17 (2001) 837-860.

[34] S. Mahajan, G.Y. Chin, Acta Metall. 21 (1973) 173-179.

[35] A.A. Salem, S.R. Kalidindi, R.D. Doherty, Acta Mater. 51 (2003) 4225-4237.

[36] D. Hull, Acta Metall. 9 (1961) 191-204.

[37] J.W. Christian, S. Mahajan, Prog. Mater. Sci. 39 (1995) 1-157. 